\title{
Entre teoria, prática e ensino, a busca de Eduardo Meditsch pela afirmação de um campo
}

\author{
Janaíne Kronbaver dos Santos ${ }^{1}$ \\ Samavel Lima²
}

\section{Resumo}

O presente artigo demonstra os principais pontos do pensamento acadêmico de Eduardo Meditsch sobre o Jornalismo enquanto forma de conhecimento e prática social de perfil aplicado. Para isso, buscou-se evidenciar o modo como o autor articula a prática e a teoria do Jornalismo com sua pedagogia, no sentido da afirmação de um campo específico de produção de conhecimento. A partir de pesquisa documental e bibliográfica desenvolvemos no artigo a descrição e análise da produção de conhecimento realizada pelo pesquisador. $O$ artigo apresenta os vértices a partir dos quais Meditsch explicita seus entendimentos sobre o Jornalismo e indica os autores referenciais do quadro teórico mobilizado por ele para a construção de sua trajetória.

Palavras-chave: Conhecimento do Jornalismo. Teoria e práxis do Jornalismo. Pedagogia do Jornalismo.

\section{Abstract}

The present article demonstrates the main points of Eduardo Meditsch's academic thinking about Journalism as a form of applied social knowledge and practice. In order to do so, we sought to show how the author articulates the practice and theory of Journalism with its pedagogy, in the sense of affirming a specific field of knowledge production. From documentary and bibliographical research we have developed in the article the description and analysis of the production of knowledge carried out by the researcher. The article presents the vertices from which Meditsch explains his understandings about Journalism and indicates the

1 Jornalista. Mestre em Comunicação e Informação (UFRGS). Doutoranda em Jornalismo (UFSC).E-mail: sjanaines@gmail.com

2 Professor e pesquisador do Departamento de Jornalismo e do Programa de PósGraduação em Jornalismo (Posjor), da Universidade Federal de Santa Catarina (UFSC). Email: samuca13@gmail.com

Revista Pauta Geral-Estudos em Jornalismo, Ponta Grossa v.5, n.2, p. 164-180, Jul/Dez 2018. 


\section{ESTUDOS EM JORNALISMO}

10.5212/RevistaPautaGeral.v.5.i2.0010

reference authors of the theoretical framework mobilized by him for the construction of his trajectory.

Keywords: Journalism knowledge. Theory and praxis of Journalism. Pedagogy of Journalism.

\section{Introdução}

Pensar na produção do conhecimento a partir do Jornalismo e na constituição de sua teoria e pedagogia são desafios assumidos por Eduardo Barreto Vianna Meditsch. Em sua trajetória, o pesquisador, identificou uma lacuna de agudo impacto para a afirmação do Jornalismo como forma social de conhecimento: a desarmonia entre proposições teóricas a ele referentes e a sua prática efetiva enquanto profissão. Meditsch entende que o campo do Jornalismo precisa defender sua especificidade de ciência social aplicada dentro da área da Comunicação Social e, diferentemente daquilo que preconiza a Ciência, necessita considerar a singularidade em torno dos acontecimentos para, a partir disso, estabelecer uma relação com o todo.

Após mais de 30 anos de dedicação à pesquisa e à docência universitária, tendo passado também pelo mercado profissional, Meditsch hoje está aposentado, mas permanece atuando como professor permanente do Curso de Pós-Graduação em Jornalismo $^{3}$ da Universidade Federal de Santa Catarina (PPGJOR/UFSC) e é pesquisador do CNPq. Professor universitário desde 1982 nesta mesma universidade, ele tem uma longa e produtiva trajetória acadêmica (o que pode ser a aferido pelos prêmios ${ }^{4}$ já recebidos), tendo atuado na gestão de cursos de graduação e pós-graduação, na liderança de grupos de pesquisa ${ }^{5}$, em entidades científicas ${ }^{6}$ e, ainda, na coordenação de atividades laboratoriais. Integrou, também, a Comissão de Especialistas que elaborou as Diretrizes Curriculares Nacionais para os Cursos de Jornalismo em 2009 e, mais

3 O PPGJOR-UFSC é o primeiro programa de pós-graduação voltado exclusivamente aos estudos sobre o Jornalismo no Brasil.

4 Dentre outros, os prêmios Vladimir Herzog de Jornalismo e Direitos Humanos, Luiz Beltrão de Ciências da Comunicação, e Adelmo Genro Filho de Pesquisa em Jornalismo.

5 Foi líder do Grupo de Investigação em Rádio, Fonografia e Áudio (Girafa), participa do Grupo Jornalismo, Cultura e Sociedade e, em 2017, criou o Grupo de Pesquisa Jornalismo e Conhecimento.

6 Além de ter coordenado o Núcleo de Pesquisa em Rádio e Mídia Sonora da Intercom, Eduardo Meditsch também já foi Diretor Científico da SBPJor, tendo ainda coordenado a Associação Latino-Americana de Investigadores da Comunicação (Alaic) e o Fórum Nacional de Professores de Jornalismo (FNPJ).

Revista Pauta Geral-Estudos em Jornalismo, Ponta Grossa v.5, n.2, p. 164-180, Jul/Dez 2018. 
recentemente, foi convidado a integrar o Comitê de Assessoramento (CA) da área de Artes, Comunicação e Informação do CNPq, cujo mandato se estende até julho de 2020.

Entre 1975 e 1979 cursou a graduação em Comunicação Social - habilitação Jornalismo, na Universidade Federal do Rio Grande do Sul ${ }^{7}$, época em que já autuava no mercado $^{8}$ e também na militância política ${ }^{9}$. É devido a sua militância e proposições na área, que Meditsch é considerado um dos principais expoentes em torno da produção do conhecimento e de uma teoria específica do Jornalismo no Brasil.

Em sua trajetória acadêmica o autor contemplou três vértices principais que se interseccionam e dão respaldo a seus posicionamentos quanto ao conhecimento produzido a partir do campo jornalístico: a Teoria do Jornalismo, sua Pedagogia e o Radiojornalismo. Neste trabalho, procurou-se dar maior atenção à recuperação de informações contidas em suas produções voltadas à reflexão acerca da Teoria do Jornalismo. Há momentos, no entanto, em que o entrecruzamento entre seus temas de interesse é inevitável.

Com três livros e dezenas de artigos publicados em livros e periódicos, Eduardo Meditsch sempre procurou estabelecer o diálogo entre a prática do Jornalismo e o conhecimento em torno dele, especialmente a partir da articulação com o ensino e sua aplicação à atividade profissional. Publicou os livros $O$ conhecimento do jornalismo (1992), O rádio na era da informação (primeiro em Portugal [1999] e depois no Brasil [2001]) e, em 2012, foi a vez de Pedagogia e pesquisa para o jornalismo que está por vir: a função social da Universidade e os obstáculos para a sua realização chegar ao público.

Esse último título reúne textos e entrevistas concedidas pelo autor ao longo de seus (até 2012) 30 anos de dedicação ao Jornalismo, além de trazer um relato pessoal anterior ao início de cada texto. Com prefácio de José Marques de Melo (seu professor à época do mestrado na USP) e apresentação de Dione Oliveira Moura (ex-presidente da

7 Paralelamente à graduação em Comunicação Social, cursava Sociologia, mas teve de interromper o curso em função das atividades profissionais que desenvolvia na época.

8 Foi editor e redator nas rádios Continental, Gaúcha, Guaíba e Jornal do Brasil, tendo desempenhado a mesma função no jornal Folha da Tarde e nas tevês Guaíba e TVE (RJ). Colaborou com a área de crítica de rádio no Jornal Público, de Lisboa. Participou, ainda, da elaboração das Normas de Redação da Rádio JB (1980) e da Rádio Gaúcha (1978).

9 Meditsch esteve envolvido com o movimento estudantil, a imprensa alternativa e 0 movimento sindical dos jornalistas de Porto Alegre. Atuou no Instituto de Estudos Políticos, Econômicos e Sociais (do MDB do RS) e, ainda, no grupo de estudos sobre Paulo Freire (iniciativa entre amigos para tentar aplicar o método de alfabetização do educador recifense em uma vila popular de Porto Alegre).

Revista Pauta Geral-Estudos em Jornalismo, Ponta Grossa v.5, n.2, p. 164-180, Jul/Dez 2018. 
SBPJor), o livro indica os caminhos trilhados por Meditsch e suas motivações para que assim fosse construída sua trajetória. Trata-se de uma obra cuja relevância transcende a esfera pessoal para elucidar "o quanto a construção de uma carreira acadêmica é um fenômeno extremamente complexo e muito imbricado com a história da construção do conhecimento" (MOURA, 2012, p. 15). O livro reúne boa parte do pensamento de Meditsch em torno daquilo que ele entende serem as demandas a atender para que se efetive a Teoria do Jornalismo. O livro em que Meditsch trabalha atualmente tem o título provisório de $A$ decepção de Pulitzer: uma história crítica do percurso do jornalismo na academia $^{10}$.

O autor é também diretor da série de livros "Jornalismo a rigor", a qual, com doze títulos, busca fortalecer a necessidade de o Jornalismo ser pensado e praticado de modo autônomo e ancorado na práxis. Além disso, Meditsch tem uma profícua participação em obras organizadas por seus pares: em 2004, participou de Teoria da comunicação: antologia de pesquisadores brasileiros, organizado por Antônio Hohlfeldt e Maria Cristina Gobbi, com o texto "O jornalismo é uma forma de conhecimento?". Pouco depois, em 2008, teve publicado no livro Jornalismo: história, teoria e metodologia da pesquisa perspectivas Iuso-brasileiras, organizado por Jorge Pedro Souza, o artigo "O jornalismo é uma forma de conhecimento: uma abordagem qualitativa". Em 2010, foi convidado a participar da obra Jornalismo e acontecimento: tramas conceituais, organizado por Virgínia Fonseca e Marcia Benetti, com o artigo "Jornalismo e construção social do acontecimento". No ano seguinte assinou, com Liriam Sponholz, o texto "Bases para uma teoria do jornalismo 2.0", prefácio da obra O poder cultural desconhecido: fundamentos da ciência dos jornais, de autoria de Otto Groth e que integra a série "Clássicos da Comunicação Social”. Além disso, organizou os títulos Rádio e pânico: a guerra dos mundos 60 anos depois (1998), os dois volumes de Teorias do rádio: textos e contextos (volumes I, em 2005, e volume II, em 2008), a tradução de Produção de programas de rádio: do roteiro à direção, de Mario Kaplún (2017) e O Ensino de Jornalismo sob as Novas Diretrizes: miradas sobre projetos em implantação (2018).

Em sua obra inaugural, O conhecimento do jornalismo, o autor apresenta uma discussão quanto à natureza do conhecimento produzido no e pelo Jornalismo frente

\footnotetext{
10 Neste título, o autor apresentará os caminhos descritos pelo Jornalismo no âmbito acadêmico nos Estados Unidos, na América Latina e na Europa. A pesquisa iniciou à época do pós-doutoramento de Meditsch.

Revista Pauta Geral-Estudos em Jornalismo, Ponta Grossa v.5, n.2, p. 164-180, Jul/Dez 2018.
} 
aquele assentado na Ciência em seu perfil clássico. Ao fazer isso, indica que ambos partem de lugares distintos para pensar a relação com seu objeto de estudo. O título, publicado em 1992, resulta de sua dissertação de mestrado, realizada junto ao curso de Pós-Graduação em Jornalismo e Editoração da USP, entre 1986 e 1990, sob orientação de Wilson da Costa Bueno. Na obra, Meditsch apresenta um texto denso, mas com linguagem e leitura acessíveis aos seus interlocutores - possivelmente inspirado pelo modo de escrever de Paulo Freire ${ }^{11}$, que foi seu professor no mestrado, mas cujos escritos ele já conhecia antes mesmo daquele período e cuja influência se faz presente no pensamento de Meditsch até hoje.

Entender aquilo que o autor exprime passa, necessariamente, por compreender as experiências por ele vivenciadas e todo o repertório que o trouxe até aqui. Seu doutorado foi realizado na Universidade Nova de Lisboa, em Portugal, sob a orientação de Nelson Traquina e Tito Cardoso e Cunha. A tese A especificidade do Rádio Informativo: um estudo da construção, discurso e objetivação da informação jornalística no rádio a partir de emissoras especializadas de Portugal e do Brasil em meados dos anos 90 foi obtida em 1997. O pós-doutorado ocorreu entre 2010 e 2011, junto à Universidade do Texas, em Austin, nos Estados Unidos, momento em que o autor se volta, novamente, à discussão sobre a produção do conhecimento a partir do Jornalismo.

Após a breve contextualização em torno dos caminhos trilhados por Eduardo Meditsch ao longo de sua vida acadêmica, avançamos, a seguir, na tentativa de apresentar os pontos que entendemos como elementares para a compreensão de seu pensamento em relação ao modo como o Jornalismo é descrito e, sobretudo, a forma como ele pode vir a ser - especialmente porque, entende Meditsch, sua potencialidade máxima ainda necessita ser explorada.

\section{O Jornalismo é uma forma de conhecimento?}

É com essa pergunta que Meditsch iniciou uma conferência (depois transformada em seu artigo mais citado quando a discussão é a teoria do Jornalismo) no Curso da Arrábida - Universidade de Verão, em Portugal, em setembro de 1997. A indagação que

11 Paulo Freire era professor visitante na Escola de Comunicação e Artes da USP à época do mestrado de Meditsch, quando ministrou a disciplina "Arte, Educação e Ação Cultural". Sobre essa experiência, Meditsch (2012, p. 47) informa: "Além de cursar esta disciplina, tive a possibilidade de debater com ele [Paulo Freire] o projeto da pesquisa, numa visita a sua casa no bairro Perdizes". 2018. 
norteia sua reflexão é a chave para que ele mesmo apresente o raciocínio que acaba por revelar seu posicionamento afirmativo quanto à pergunta: sim, o Jornalismo produz conhecimento. Este, no entanto, é um conhecimento de tipo específico, único e original se comparado ao produzido pela ciência ou pela arte: "o Jornalismo não revela mal nem revela menos a realidade do que a ciência: ele simplesmente revela diferente. $E$ ao revelar diferente, pode mesmo revelar aspectos da realidade que os outros modos de conhecimento não são capazes de revelar" (MEDITSCH, 2008, p. 3).

Para o autor, ao propor uma forma de compartilhamento e socialização de informações peculiar, o Jornalismo torna possível que novos aspectos da realidade social sejam evidenciados. Isso permite que seja descontruída a ideia de solidez inequívoca habitualmente atribuída ao conhecimento científico para se pensar em uma perspectiva de maior complexidade.

O Jornalismo, ao se "fixar na imediaticidade do real", passa a considerar o "campo lógico do senso comum" (MEDITSCH, 2008, p. 6) e, mais do que isso, "realiza para o público as mesmas funções que a percepção realiza para os indivíduos", conforme já havia proposto Robert Park ${ }^{12}$. É como se o Jornalismo assumisse uma responsabilidade para com as impressões gerais acerca do mundo disponíveis ao público, a partir das quais, inclusive, podem ser estruturadas diferentes representações sociais.

Em constante processo de conformação, o Jornalismo parte do previamente já sabido, no âmbito do senso comum, para atualizar e contextualizar as informações a ele inerentes. Para isso, insere elementos novos ao contexto informativo, o que reverbera no conhecimento público acerca dos fatos. No que se refere ao contexto informativo, inclusive, é preciso ter claro que o "conteúdo do jornalismo" está sempre "preso ao senso comum" - como já propunha Park (1940) - do mesmo modo que também está "necessariamente vinculado a um contexto" dado (MEDITSCH, 2008, p. 9). A partir desse panorama, pode-se afirmar que é da articulação entre senso comum, contexto situacional e nova informação que emana a produção do conhecimento jornalístico.

E se a ciência em particular (e a vida acadêmica em geral) se afirma em oposição ao senso comum, isso talvez explique a dificuldade que tem para compreender a natureza do jornalismo. Entender o senso comum é

12 PARK, Robert. A notícia como conhecimento: um capítulo da Sociologia do conhecimento. In: STEINBERG, Charles. Meios de comunicação de massa. São Paulo: Cultrix, 1940.

Revista Pauta Geral-Estudos em Jornalismo, Ponta Grossa v.5, n.2, p. 164-180, Jul/Dez 2018. 
fundamental para compreender os processos cognitivos envolvidos na comunicação jornalística e a participação do jornalismo na produção dos acontecimentos e, consequentemente, na construção da realidade (MEDITSCH, 2010, p. 36).

Sem tempo hábil para a produção de informações em maior profundidade requisito primordial ao conhecimento científico -, o conhecimento jornalístico é estruturado de modo "menos rigoroso" se comparado ao "de qualquer ciência formal". No entanto, ao ser menos distante da vida cotidiana dos sujeitos, ele acaba sendo igualmente "menos artificial e esotérico" (MEDITSCH, 2008, p. 7). O autor entende que a Ciência e o Jornalismo mantêm uma distância entre si porque, diferente da primeira, o Jornalismo "não descartou o generalismo. Pelo contrário, encontra neste generalismo uma de suas principais funções sociais: a de manter a comunicabilidade entre o físico, o advogado, o operário e o filósofo" (MEDITSCH, 1992, p. 55).

O conhecimento produzido pelo Jornalismo, assim, "não parte de uma hipótese nem de sistema teórico anterior, mas da observação não controlada [...] da realidade por parte de quem o produz" (MEDITSCH, 1992, p. 72). Assim, a hipótese científica se aproximaria daquilo que acaba por definir a pauta jornalística, a qual teria "maior possibilidade", inclusive, "de revelar o novo por estar vinculado ao mundo sensível a partir do singular".

Ao fazer menção ao singular, o autor resgata as proposições de Adelmo Genro Filho $^{13}$, o qual argumenta que é a partir da singularidade que o Jornalismo estabelece seu ponto de partida, a sua especificidade enquanto campo do conhecimento, articulando-se, também, às categorias de particular e universal. Com uma natureza diversa da vinculada ao conhecimento científico, o Jornalismo se ocupa com as ocorrências que interferem no cotidiano da vida social, considerando o senso comum e as intercorrências que de algum modo nele interferem e terão efeitos sobre a vida das pessoas. Advém dessa característica a própria dificuldade para sua sistematização, conforme os parâmetros que balizam o conhecimento científico. Para Meditsch (2008, p. 9), “Jornalismo não é uma 'ciência malfeita', simplesmente porque não é uma ciência e nem pode aspirar a ser tal".

13 Adelmo Genro Filho é autor de O segredo da pirâmide: para uma teoria marxista do jornalismo, com primeira edição publicada em 1987 a partir de sua dissertação de mestrado. À época professor do curso de Jornalismo da UFSC, Adelmo faleceu de modo precoce, deixando um legado a ser mais bem explorado por seus colegas docentes; dentre eles está Eduardo Meditsch.

Revista Pauta Geral-Estudos em Jornalismo, Ponta Grossa v.5, n.2, p. 164-180, Jul/Dez 2018. 
"Patinho feio do conhecimento" (MEDITSCH, 1992), o Jornalismo é entrecortado por mediações. Essa característica reflete diretamente sobre o conteúdo disponibilizado na forma de notícia. Meditsch $(2008$, p. 11) propõe que as principais mediações que interferem no Jornalismo relacionam-se à falta de transparência com que atuam os agentes do processo noticioso, a velocidade com a qual se opera a construção da informação e o viés espetaculoso fixado na notícia para que a atenção do público seja cativada. Mesmo adscrito a elementos que podem desaboná-lo, o Jornalismo, inegavelmente, "[...] reproduz a sociedade em que está inserido, suas desigualdades e suas contradições", do mesmo modo que outras formas de conhecimento igualmente estão sujeitas a esse condicionamento.

As mediações são inerentes à vida dos sujeitos, as presentes no âmbito do Jornalismo qualificam apenas uma de suas interfaces. Da mesma forma que a informação jornalística informa e atualiza o cidadão sobre aquilo que ocorre no meio social (muitas vezes não fazendo isso de modo desinteressado), ela não assume essa função de maneira isolada, pois cada indivíduo se relaciona também com "outras redes de informação". Essas, por sua vez, transcendem o espectro jornalístico e podem oportunizar ao indivíduo maior discernimento quanto ao que é informado e realmente assumirá relevância para sua vida.

Em consonância com esse entendimento, Meditsch (2010) propõe que o Jornalismo não constrói a realidade ${ }^{14}$, apenas intervém de modo auxiliar nesse processo. O autor é crítico à ideia de que essa construção ocorra exclusivamente a partir daquilo que é veiculado a partir das notícias, pois isso conferiria poder quase absoluto à informação jornalística, ignorando a complexidade que marca a inserção social dos sujeitos.

O jornalismo, por fim, participa da socialização do conhecimento, ainda que de forma terciária e provavelmente menos marcante que as socializações primária e secundária observadas por Berger e Luckmann na construção social da realidade, embora igualmente importante na dinâmica social (MEDITSCH, 2010, p. 41).

\footnotetext{
14 Aqui Meditsch se refere ao entendimento clássico proposto por Berger e Luckmann em A construção social da realidade (1973) e que teria recebido uma tradução equivocada quando apropriado pelos estudos em Jornalismo.

Revista Pauta Geral-Estudos em Jornalismo, Ponta Grossa v.5, n.2, p. 164-180, Jul/Dez 2018.
} 
A partir daquilo que é veiculado como notícia ocorre um processo de construção, no entanto ele é parcial (com angulações, enquadramentos, subjetividades, etc.) e interatua de forma complementar ao processo de circulação de informação e conhecimento social. Assim, mesmo que o Jornalismo não exerça um papel de centralidade na vida dos sujeitos, sua relevância não pode ser ignorada.

Decorre desse contexto a importância de o jornalista assumir um posicionamento ético e político em seu fazer profissional. Para o autor, é a partir da sua conduta que o jornalista vai poder levar a efeito a práxis. Assim, ao tomar uma posição ética e política, o jornalista deve buscar manter uma conduta coerente com aquilo que a práxis sugere: ir a campo, reportar os acontecimentos e, com isso em mãos, realizar seu trabalho (de maneira responsável e de acordo com as balizas que guiam sua ação consciente) para, finalmente, buscar intervir na esfera social com a produção do conhecimento que the é característico.

Ignorar que o Jornalismo produz um tipo específico de conhecimento prejudica tanto o ensino quanto a sua prática, que fica reduzida a algo puramente técnico, com a submissão dos jornalistas (aqueles que produzem esse conhecimento) às empresas que os contratam. A solução para esse problema, em seu entendimento, está numa pedagogia "[...] que se proponha a formar profissionais efetivamente críticos e competentes, criativos e capazes de transformar a realidade" (MEDITSCH, 1992, p. 81). Para o autor, no entanto, a práxis (constituída a partir da ação prática efetiva e a consequente reflexão de seu agente) teve seu sentido esvaziado a partir do instante em que ficou no meio-termo entre a teoria e a prática. Seu verdadeiro significado indica a prática consciente acerca daquilo que se faz, não com viés meramente conceitual ou teórico.

É nesse sentido que Meditsch (2008, p. 11) visualiza a necessidade premente de a legitimidade do campo jornalístico ser estabelecida e postula por sua efetiva admissão enquanto espaço de produção de conhecimento. A partir desse reconhecimento, tanto das práticas profissionais quanto de seu produto final, a notícia, podem ser exigidos maior cuidado e precisão, uma vez que o "conhecimento implica em aperfeiçoamento pela crítica e requer rigor". Para que isso ocorra, no entanto, é preciso vontade política.

A seguir se procura evidenciar o cenário em que o Jornalismo está inserido e os reveses que tangenciam sua trajetória enquanto campo de conhecimento, aspecto presente de modo importante na trajetória de Meditsch, que tenciona o reconhecimento da 2018. 
especificidade do campo do Jornalismo (enquanto ciência social aplicada) frente à área de Comunicação.

\section{Entre a teoria e a prática do Jornalismo, um hiato}

No livro que resulta de sua pesquisa de mestrado, Meditsch aponta para a distância existente entre o Jornalismo que é pensado/ensinado na academia e aquele que se produz no âmbito profissional. Essa inquietação o aflige, pois tem efeitos marcantes sobre a trajetória final descrita pelo Jornalismo, cuja conformação fica absolutamente descolada daquilo que seria seu modelo ideal, a partir da perspectiva acadêmica. Em sua leitura, "não foi ainda desatado o nó que desde sempre tem impedido a coerência entre teoria e prática no ensino e na pesquisa do Jornalismo" (MEDITSCH, 2012, p. 23).

Ao comentar sua trajetória profissional e formação superior, Meditsch (1992) dá testemunho sobre a existência dessa incongruência entre a teoria e a prática do Jornalismo: aos 21 anos, após concluir a graduação, ele tornou-se editor de uma reconhecida emissora de rádio de Porto Alegre (na qual já atuava como repórter) e pôde verificar, as diferenças entre aquilo que era realizado nesse ambiente e o que se aprendia na universidade.

Ao analisar aquele período, o autor aponta para a existência de um "intelectocentrismo acadêmico" em contraposição a um "ferramentismo do mercado" - o que se constitui em um empecilho para o reconhecimento do Jornalismo como uma forma de conhecimento legítima, pois ambos não dialogam e caminham em sentidos opostos. No entendimento de Meditsch (1992, p. 54), há "um limite metodológico da teoria ensinada na faculdade, que a impede de se transformar numa Ciência do Jornalismo, absorvendo a prática para superá-la".

Esse limite se relaciona à tentativa de enquadrar o Jornalismo dentro da lógica mais ampla da Ciência. Com isso sua especificidade, partir do singular para o universal (conforme propunha Genro Filho), é perdida e o Jornalismo torna-se refém de um sistema incapaz de mirar o potencial latente dessa área do conhecimento. Essa situação vinculase ao perfil do conhecimento produzido pela ciência, com estreita aproximação com o positivismo, pois primeiro parte-se da reflexão teórica para depois avançar-se rumo à sua aplicação prática. No caso do Jornalismo, o que Meditsch propõe é o contrário.

O autor sugere a inversão na lógica dominante acerca da produção do conhecimento para que se possa compreender aquele que seria o autêntico lugar do Revista Pauta Geral-Estudos em Jornalismo, Ponta Grossa v.5, n.2, p. 164-180, Jul/Dez 2018. 
Jornalismo. Nesse sentido, propõe que sua teoria busque, "justamente, afirmar o primado da prática" (MEDITSCH, 1992, p. 58) para efetivar-se. Não se trata de uma negação ingênua da teoria, mas da busca por sua fundamentação a partir da prática para, a seguir, investir-se, com relevo, na sua construção teórica.

Essa sugestão desacomoda a rotina já estabelecida e perpetuada no ambiente acadêmico, daí a dificuldade para seu acolhimento. Ainda em relação a esse distanciamento, é preciso considerar que "a prática", até hoje, continua a ser visualizada "numa escala inferior da hierarquia" acadêmica (MEDITSCH, 2012, p. 111).

Existem, além da dicotomia entre a teoria e a prática do Jornalismo, pelo menos outros quatro elementos impeditivos para que sua pesquisa e, consequentemente, sua teoria, ocorram. Meditsch os indica pontualmente em um texto original de 2001 (presente em sua coletânea de 2012) e pode-se depreender que todos estão interconectados e se vinculam também a uma dimensão política. Trata-se dos problemas de qualidade, identidade, legitimidade e cientificidade.

A área da Comunicação Social tem um perfil incipiente em termos de produção autônoma, quanto mais no que se refere à subárea do Jornalismo. Por ser uma ciência social aplicada e, portanto, de valor “'menor' no âmbito acadêmico”, entende-se que seus resultados estejam distantes daqueles gerados pelo "conhecimento pelo conhecimento", atribuído às áreas científicas clássicas (MEDITSCH, 2012, p. 107), e, mais do que isso, visualiza-se, inclusive, possibilidade de jamais haver uma consideração acerca do conhecimento que o Jornalismo produz. Nesse sentido, a falta de tradição na produção acadêmico-científica da área acaba por vitimar tanto o Jornalismo quanto sua estruturação enquanto campo.

Alia-se a essa perspectiva o fato de a identidade da Comunicação até hoje não ser bem delineada, incorporando saberes, procedimentos metodológicos e técnicos importados de outras áreas do conhecimento. Essa falta de autonomia acabou por tornar possível sua colonização por parte de outros campos que a tomam quase que exclusivamente como objeto de estudo. "Isso talvez explique por que cientistas sociais, pedagogos e filósofos continuem sendo as principais referências teóricas de nossa área, em vez de comunicólogos" (MEDITSCH, 2012, p. 109).

Também vem de outras áreas vários dos professores que atuam junto aos cursos de Comunicação, daí que os "caminhos teóricos" (MEDITSCH, 2012, p. 111) percorridos permaneçam submetidos ao olhar desse ente externo, com foco desvirtuado daquele que Revista Pauta Geral-Estudos em Jornalismo, Ponta Grossa v.5, n.2, p. 164-180, Jul/Dez 2018. 
seria o de seu objeto primordial. Esse processo, praticamente um tabu no âmbito das associações e programas de pós-graduação, é cíclico e intervém, igualmente, na falta de tradição acima referida.

Quanto ao problema da legitimidade, Meditsch (2012, p. 112) propunha, já em 2001, ser necessário recuperar o objeto de estudo da Comunicação. Isso significava que, além de fazer a crítica às produções da área, era preciso buscar compreender "seu funcionamento interno" e sua "relação com o contexto". Nesse sentido, o autor entendia ser cada vez mais necessária a busca pela autonomia da Comunicação e do Jornalismo em específico, algo para o qual o próprio curso de graduação em Jornalismo da UFSC trabalhou, numa ação com a qual foram criados, ainda, um curso de especialização lato sensu, em 2001, e posteriormente um curso de pós-graduação stricto sensu, em 2007 cujo apogeu deu-se com a estruturação do curso de doutorado, em 2014 (MEDITSCH; AYRES; BETTI, 2017). Esse processo foi marcado por embates dentro da área e pela falta de reconhecimento e aceitação de muitos dos pares acadêmicos acerca da importância dessa iniciativa.

A questão da cientificidade é o último dos pontos apresentados por Meditsch para que a pesquisa em Jornalismo se desenvolva de modo pleno. Para ele, enquanto fizermos uso de instrumentos e técnicas advindas de outras áreas para produzir o conhecimento que nos alimenta, não seremos consistentes em termos metodológicos. A coerência é imprescindível à consistência da produção do conhecimento. Por isso, devem-se buscar caminhos metodológicos congruentes com as perguntas de pesquisa que se anseia responder.

A partir de todos esses aspectos é que Meditsch (1992, p. 71) afirmava que o objeto de pesquisa do Jornalismo encontrava-se perdido: "O mero reconhecimento de uma realidade não leva necessariamente a sua transformação, e o sujeito está submetido a outros condicionamentos internalizados, além daqueles provocados pelo objeto perdido". O que permitiu que essa seja a realidade estabelecida nos dias atuais remonta ao período da Guerra Fria, com a implantação do CIESPAL (Centro Internacional de Estudos Superiores de Comunicação para a América Latina) em Quito, no Peru, e é explicado por Meditsch em sua pesquisa de mestrado. Hoje o movimento protagonizado pelo Programa de Pós-Graduação em Jornalismo da UFSC caminha no sentido de fortalecer a pesquisa em Jornalismo especificamente, mas já encontrou (e encontra ainda) algumas barreiras para seu avanço, inclusive dentro de seu próprio programa. 2018. 


\section{O Jornalismo em busca de autonomia teórica}

Pensar a teoria é um desafio imediato no horizonte da pesquisa em Jornalismo. Meditsch tem apresentado contribuições que procuram desnudar, além dos pontos cegos inerentes ao próprio Jornalismo enquanto campo do conhecimento, fatores que lhe são exteriores e interferem nessa busca. Se, de uma perspectiva, a pesquisa em Jornalismo procura responder a questões pontuais sobre a prática profissional, de outra, sua reflexão teórica é ainda claudicante, como indica o levantamento sobre o percurso da pesquisa teórica sobre Jornalismo no PPGJOR-UFSC em sua primeira década (MEDITSCH; AYRES; BETTI, 2017).

Para Meditsch (2017), também contribuem para esse cenário a dissonância entre a proposta de novas diretrizes curriculares para os cursos de graduação em Jornalismo ${ }^{15} \mathrm{e}$ a desregulamentação ${ }^{16}$ da profissão. Esses elementos, deflagrados em 2009 e com reverberações visíveis até hoje, associados ao clima de insegurança teórico-conceitual da área, geram efeitos sobre o modo como o campo do Jornalismo se institucionaliza e, mais do que isso, sobre a busca pela consolidação de seu perfil epistemológico e, portanto, de sua matriz teórica.

Diferente de outras profissões, o Jornalismo não conseguiu ter força suficiente para transcender o status de ocupação e assumir o lugar de uma profissão (com uma filosofia que a subsidiasse). Além disso, a fragilidade central do Jornalismo recai sobre "a falta de consenso interno sobre o que é o jornalismo e sobre os critérios de competência para exercê-lo, ou seja, a falta de clareza teórica sobre a atividade" (MEDITSCH, 2017).

Do mesmo modo, a interdisciplinaridade da qual a área da Comunicação se utiliza e seu perfil de "quase disciplina" em nada auxiliam para a verticalização em torno de uma efetiva teoria do Jornalismo. Nesse sentido, a "Teoria da Comunicação não apenas limitou a compreensão teórica do Jornalismo" como também a impossibilitou (MEDITSCH, 2017). Meditsch propõe que observar o Jornalismo a partir de seu vínculo com a mídia ou com a

15 Em seu trabalho de mestrado Meditsch defendia que o ensino nos cursos de Jornalismo tivesse como premissa a realização de atividades práticas para que ao longo do curso fossem introduzidos aportes teóricos para direcionar a reflexão em torno da realidade cotidiana. É isso o que ele também defendeu na comissão que reestruturou os currículos dos cursos de Jornalismo.

16 Para Meditsch (2017), a queda da exigência de diploma para o exercício do Jornalismo "teve entre suas causas mais importantes um evidente fracasso da área acadêmica em construir teoricamente a profissão".

Revista Pauta Geral-Estudos em Jornalismo, Ponta Grossa v.5, n.2, p. 164-180, Jul/Dez 2018. 
Comunicação pode ser interessante; no entanto, isso não contribuirá para que sejam fortalecidos o olhar e a compreensão da sua teoria e das especificidades que lhe cortam.

O compromisso com a prática situa a Jornalística, inexoravelmente, como uma disciplina aplicada. Quando a Comunicologia caminha em sentido oposto, no sentido de se afirmar como ciência humana estritamente crítica e de se afastar de sua origem (identificada com as práticas profissionais do campo), a tendência é de um distanciamento inevitável entre objetos, propósitos e metodologias (MEDITSCH, 2017).

É nesse contexto que os caminhos se confundem, configurando aquilo a que o autor se refere como "pantanal teórico", pois tanto a Comunicação quanto o Jornalismo buscam ainda reconhecimento e legitimação nos campos acadêmico-científico e profissional. Esse pleito os coloca em espaços diametralmente opostos e sob ataque constante: "a Teoria da Comunicação e a Teoria do Jornalismo são muito parecidas em suas dificuldades, superpostas em seus objetos e diferentes em seus objetivos", daí a não concordância ou dissenso entre as partes.

Ao se tomar o Jornalismo, a mídia e a Comunicação como objetos de estudo (concepção defendida pela Comunicação Social), pode-se visualizar que a Teoria da Comunicação deixa de responder às especificidades suscitadas pelo objeto de estudo específico do Jornalismo. Este, por sua vez, encontra na sua dimensão de disciplina aplicada o veio que permite o fortalecimento de sua identidade, com características diferentes das atribuídas à Comunicação, e, consequentemente, sua autonomia epistemológica e profissional. A questão da autonomia ou submissão das disciplinas científicas somente pode vir a ser resolvida quando as disputas pelo poder dentro das instituições e entre os pares forem superadas.

Nesse arranjo, no entendimento de Meditsch, e de acordo com a leitura proposta por Joaquim Fidalgo ${ }^{17}$ (2008),

a ausência de uma teorização própria é um dos principais obstáculos ao reconhecimento social da profissão. Ao mesmo tempo, a incapacidade da área acadêmica de fornecer à prática um suporte teórico pertinente leva também a uma desmoralização do ensino superior (MEDITSCH, 2017).

17 FIDALGO, Joaquim. O jornalista em construção. Porto: Porto Editora, 2008. 
Ainda segundo Meditsch (2017), para avançar no campo epistemológico, primeiro o Jornalismo precisa se justificar enquanto profissão e, paralelamente, como disciplina científica. A partir disso e também vinculado à dimensão epistemológica do campo, "é preciso distinguir entre teoria, disciplina e área de conhecimento". Com essa distinção, "muito debate estéril" poderia ter sido evitado e seria possível avançar em busca de um consenso mínimo.

Meditsch considera ser necessário separar o Jornalismo em estratos específicos para facilitar sua compreensão, pois vários significados estão atrelados ao termo. Assim, em sua proposta, a prática profissional seria denominada de jornalismo; a disciplina que estuda essa prática, por sua vez, seria a jornalística (como propôs Otto Groth ${ }^{18}$ ). Um terceiro momento do Jornalismo seria aquele relacionado a sua pedagogia, instante em que ocorreria, ainda que idealmente, a associação entre a teoria e a prática.

Meditsch produziu a tabela a seguir na busca por elucidar suas proposições:

Tabela 1 - Tipos de conhecimento no curso de Jornalismo

\begin{tabular}{|c|c|c|c|c|c|}
\hline \begin{tabular}{|l|} 
Tipo de \\
conhecimento
\end{tabular} & $\begin{array}{l}\text { Etapa do } \\
\text { oconhecimento }\end{array}$ & $\begin{array}{l}\text { Método } \\
\text { otilizado }\end{array}$ & Objeto & Produto & Ação \\
\hline do Jornalismo & $\begin{array}{l}\text { Criação de } \\
\text { novo } \\
\text { conhecimento }\end{array}$ & Jornalístico & Fatos da atualidade & $\begin{array}{l}\text { Cobertura } \\
\text { jornalística }\end{array}$ & Prática \\
\hline $\begin{array}{l}\text { sobre o } \\
\text { Jornalismo }\end{array}$ & $\begin{array}{l}\text { Criação de } \\
\text { novo } \\
\text { conhecimento }\end{array}$ & Científico & $\begin{array}{l}\text { Jornalismo como } \\
\text { fenômeno }\end{array}$ & $\begin{array}{l}\text { Teoria do } \\
\text { Jornalismo }\end{array}$ & Pesquisa \\
\hline $\begin{array}{l}\text { para o } \\
\text { Jornalismo }\end{array}$ & $\begin{array}{l}\text { Conhecer o } \\
\text { conhecimento } \\
\text { existente }\end{array}$ & Pedagógico & $\begin{array}{l}\text { oTeoria e prática do } \\
\text { Jornalismo (mais } \\
\text { Teoria da } \\
\text { Comunicação, } \\
\text { Ciências Humanas, } \\
\text { etc.) }\end{array}$ & $\begin{array}{l}\text { Profissional } \\
\text { para a } \\
\text { práxis }\end{array}$ & $\begin{array}{l}\text { Ensino- } \\
\text { Aprendizagem }\end{array}$ \\
\hline
\end{tabular}

Fonte: Meditsch (2017)

As informações da tabela revelam que, para Meditsch, o Jornalismo relaciona-se com três tipos diferentes de conhecimento. O primeiro vincula-se à prática profissional e é

18 GROTH, Otto. O poder cultural desconhecido: fundamento da Ciência dos Jornais. Petrópolis, RJ: Vozes, 2011.

Revista Pauta Geral-Estudos em Jornalismo, Ponta Grossa v.5, n.2, p. 164-180, Jul/Dez 2018. 
produzido a partir da cobertura jornalística (a qual toma como objeto os fatos da atualidade e usa o método jornalístico para se estruturar). A seguir, tem-se a dimensão da pesquisa, com viés científico e foco na Teoria do Jornalismo. Seu objeto apreende o Jornalismo como um fenômeno, produzindo conhecimento acerca dele. A última instância é a que se relaciona ao processo de ensino-aprendizagem (pedagógico, portanto) proporcionado pelo Jornalismo; seu objeto é mais amplo que os anteriores e dialoga, ainda, com as Ciências Humanas e a própria Teoria da Comunicação.

\section{Considerações finais}

Para desatar o amalgamado de nós em que se encontra o Jornalismo é imprescindível que haja maior clareza em relação ao todo que estrutura a arena em que ele está inserido. Nela é possível identificar, dentre outros elementos, um legado histórico de viés unilateral em prol da Comunicação Social e a falta de articulação entre os próprios jornalistas para afirmar a autonomia de sua identidade profissional e acadêmica.

Recuperar a trajetória de Eduardo Meditsch, suas produções e proposições, é um exercício que permite visualizar o longo e desafiador caminho a ser descrito pelo Jornalismo, que em seus dias atuais enfrenta rupturas paradigmáticas e descontinuidades até aqui inéditas. Se no âmbito acadêmico há disputas políticas e dissensos entre os pesquisadores, também no mercado profissional identifica-se uma frágil perspectiva reflexiva em torno das práticas e uma aguda preocupação com as técnicas em torno da profissão.

A proposição de Meditsch, ao sugerir um ordenamento para as diferentes instâncias com as quais o Jornalismo se vincula, joga luz sobre o contexto turvo em que se encontram esses diferentes atores sociais, seus interesses e respectivos posicionamentos políticos. É urgente que a abertura para o diálogo entre os participes dessa complexa relação seja estabelecida.

\section{Referências}

MEDISTCH, Eduardo. Jornalismo e construção social do acontecimento. In: BENETTI, Marcia; FONSECA, Virgínia P. S. (Orgs.) Jornalismo e acontecimento: mapeamentos críticos. Florianópolis: Insular, 2010.

MEDISTCH, Eduardo. Informação sobre novo livro. [mensagem pessoal] Mensagem recebida por: <sjanaines@gmail.com> em: 30 abr. 2018. 
MEDISTCH, Eduardo.O conhecimento do jornalismo. Florianópolis: Ed. da UFSC, 1992.

MEDISTCH, Eduardo. O Jornalismo é uma forma de conhecimento? In: SOUSA, Jorge Pedro. Jornalismo: história, teoria e metodologia da pesquisa - perspectivas lusobrasileiras. Porto: Edições UFP, 2008. p. 7-12.

MEDISTCH, Eduardo. Pedagogia e pesquisa para o Jornalismo que está por vir: a função social da Universidade e os obstáculos para a sua realização. Florianópolis: Insular, 2012.

MEDISTCH, Eduardo. Tipos e formas de conhecimento na Escola de Jornalismo. In: ALMEIDA, Fernando Ferreira; CARILHO, Kléber; BASTOS, Robson (Orgs.) Fórum Ensinocom: realidades e perspectivas do ensino de comunicação no Brasil. São Paulo: Intercom, 2017.

MEDISTCH, Eduardo; AYRES, Melina de la Barrera; BETTI, Juliana Gobbi. Dez anos do POSJOR UFSC: relato do percurso e perfil da produção. Estudos em Jornalismo e Mídia, v. $14, \quad$ n. $1, \quad$ p. $75-88,2^{\circ}$ semestre de 2017 . Disponível em: https://periodicos.ufsc.br/index.php/jornalismo/article/view/1984-6924.2017v14n2p75.

<Acesso em: 09 jan. 2018>.

MOURA, Dione Oliveira. 30 anos não são trinta dias. In: MEDITSCH, Eduardo. Pedagogia e pesquisa para o Jornalismo que está por vir: a função social da Universidade e os obstáculos para a sua realização. Florianópolis: Insular, 2012.

Recebido em: 26/05/2018

Publicado em: 21/12/2018 